\title{
Inductive teaching approaches in business English writing in an EFL context: Paper-based and product-based instructions
}

\author{
Piyawan Rungwaraphong \\ Faculty of Commerce and Management \\ Prince of Songkla University, Trang Campus, 102 Khuan Pring, Mueang Trang District, Trang 92000, Thailand \\ piyawan.r@psu.ac.th
}

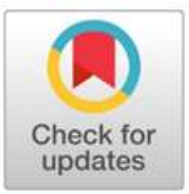

\section{ARTICLE INFO}

\section{Article history}

Received 15 December 2021

Revised 16 April 2021

Accepted 20 April 2021

\section{Keywords}

English writing

EFL

inductive

tangible

teaching

\section{ABSTRACT}

The study reported in this article compared two different inductive instructional methods implemented in a Business English writing training, including paper-based instruction (PPI) and product-based instruction (PDI). It assessed the effectiveness and examined practical issues of the implementation of each method. A total of 46 Thai students majoring in a Business English program at a Thai university participated in this study. The students were randomly divided into two groups and put into either the PPI or PDI training module. The researcher collected data from direct observations, focused-group discussions, and students' writing scores. Qualitative data from the focused-group discussions and observation field notes were analyzed thematically using the grounded theory, while cross-examination was utilized for students' writing scores. The study results indicate that the fundamental dichotomies between both approaches include tangibility, authenticity, and contextuality. Students' difficulties in formulating grammar and writing rules on their own and students' perception of learning as a burden were found as challenges in both modules. The findings also indicate that both the PPI and PDI modules trigger classroom dynamics and a positive atmosphere; however, PDI resulted in more vigorous dynamics as student movements and interactions were relatively higher. Finally, this study's findings are beneficial for instructors seeking innovative instructional methodology to improve their Business English writing teaching. The study has contributed to the field of teaching Business English writing. The study's findings have helpful implications for lecturers of Business English writing, who are looking for a teaching approach that enables them to create opportunities for students to learn in authentic, professional environments, contexts, and cultures cast in real-life business situations.

This is an open-access article under the CC-BY-SA license.

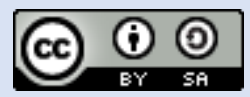

How to Cite: Rungwaraphong, P. (2021). Inductive teaching approaches in business English writing in an EFL context: Paper-based and product-based instructions. English Language Teaching Educational Journal, 4(1), 34-48. doi.org/10.12928/eltej.v4i1.3227

\section{Introduction}

In EFL contexts, the goal of Business English writing courses provided in higher education is dual: firstly, to improve students' command of business-related English, and secondly, to provide a good grounding and adequate understanding of the principles of business so that students can create business-related content. Challenges in teaching Business English writing for EFL students are student engagement in writing tasks and covering the writing materials or tasks. Additionally, particularly in EFL contexts, uncovering teaching approaches that assist students in achieving the dual goal of Business English writing is essential. However, literature undertaken so far suggests significant 
differences between Business English writing in educational contexts and English writing required in real-life business situations (Hollis-Turne \& Scholtz, 2010). It is important that business writing courses consist of learning activities and tasks that enable students to transfer knowledge from the classroom to what is required of them in the workplace. This suggests a need for a teaching approach that will create a linkage between the two situations; the approach, at the same time, must not forget to focus on the development of the grammatical and syntactic aspects of the English language.

In searching for an instructional approach that ensures both students' development of English writing competence and the capability to transfer writing skills from the academic environment to the workplace, the researcher framed two instructional methods upon the theory of inductive references. Both teaching methods involve the students observing examples of the target language provided by the teacher, identifying patterns or concepts implicit in those examples, formulating rules or principles, and applying or creating a piece of work using those rules or principles in the target language. The differences exist in the process of eliciting data for the writing. The study reported in this article seeks to evaluate and compare the implementation and the challenges of the two instructional approaches implemented in English writing contexts; both are inductive-based and designed by the researcher to serve the dual goal of Business English writing teaching. The inductive instruction methods investigated include Paper-Based Instruction and Product-Based Instruction (hereafter called PPI and PDI, respectively). Results from this study make contributions to the field of teaching Business English writing. The study's findings have helpful implications for lecturers of Business English writing, who are looking for a teaching approach that enables students to write professionally and learn in authentic, professional environments.

\subsection{Business Writing in Real Business Vs. Academic Contexts}

Business writing courses provided in academic contexts aim to ensure that students become competent in producing business writing genres that they will be required to produce in the workplace. However, literature about business writing indicates a vast difference between business writing courses provided by educational institutions and business writing required by graduates to complete in real business environments. The difference is rooted in the fact that business writing offered at universities is influenced by educational policies and educational requirements such as curriculum and assessment. Likewise, Hollis-Turner and Scholtz's (2010) study of business writing in academic and workplace contexts claims that the disjuncture results from the different requirements that higher education and the real-life working world have.

Recognizing the above disjuncture, business writing lecturers try to stimulate business writing prevalent in real business contexts. However, they frequently have "to simplify and de-contextualize" (Hollis-Turner\& Scholtz, 2010, p.241) documents and learning tasks for learning purposes. The decontextualization of teaching business writing also occurs because of the audience. Al-Mohammadi and Derbel (2015) pointed out that the teacher is the sole audience of students' works in the classroom. However, the students may not perceive their teacher as the audience of their writing; instead, they generally perceive the teacher as the evaluator. The study's findings claim that students' awareness of the audience is important as it affects their writing performance. The study suggests that decontextualized writing activities should be avoided, and the teacher should clearly define the "particular audience" in all writing tasks and assignments. The study by Albino (2015) examined the effect of an explicit genre-based approach to teaching writing for learners of English as a foreign language in the workplace. The study results suggest that an explicit genre-based approach is a suitable approach in teaching writing for the workplace for EFL learners.

Whether business writing should be taught with contextualization or de-contextualization, or implicitly or explicitly, is still controversial. No matter which approach is employed in teaching business writing, contextualizing or de-contextualizing, or explicitly or implicitly, the lecturers need to be aware of the demands of the real business world and train the students to meet the demands of the business world (Arputhamalar \& Kannan, 2015). This signifies that learning activities or exercises in class must be designed in ways that bridge the gap between academic and business contexts while enhancing students' capability to transfer what is taught in the classroom to what is required in the workplace (Hollis-Turner \& Scholtz, 2010). 


\subsection{Deductive \& Inductive Approaches}

Nunan (1999) described the deductive teaching approach as the instructional method that begins with "rules and principles and then applies the rules to particular examples and instances" (p.305). Examples given to students are often de-contextualized, and the students may not be required to make meaning of the structures presented. At the end of the lesson, the students produce their sentences by applying the rules highlighted by the teacher (Thornbury, 1999). In this light, deductive teaching underlines top-down reasoning, moving from more general to more specific.

In contrast to the deductive approach, the inductive approach works the other way around. It is called a "bottom-up" approach, deriving general rules and principles from specific examples. According to Thornbury (1999), the inductive approach begins with the examples given to the students. The students then observe and notice patterns implicit in the examples provided. They formulate the rules or principles, and after that, apply the patterns or rules in the target language. Rizzuto (1970) regarded the inductive method as the discovery experience in which the learner is accompanied by the teacher's guidance and verbal cues. However, the deductive method is regarded as a "didactic expository" (Rizzuto, 1970, p. 269) learning mode. Learners do not need to make any discovery and are directly exposed to the lessons. The experimental comparison of both deductive and inductive methods concluded that the inductive approach is the superior language teaching method. The deductive method brings about greater learning in the initial stage, and the time it takes to learn is diminutive. In contrast, the inductive method consumes more time as it requires students to discover language structure concepts independently. However, it renders better retention in the long term.

In the same light, Thornbury (1999) notes that knowledge acquired through inductive instructional methods is more profound than ones through deductive methods. An inductive approach, as compared to a deductive approach, is a more complex and indirect instructional method and functions in the higher level of the learner's cognitive domain. According to Rüütmann and Kipper (2011), the sequence of learning - "facts-rules-action" in the deductive approach and "concepts-patternsabstractions" in the inductive approach - results in differences in learning outcomes, particularly problem-solving and critical-thinking. Importantly, inductive teaching methods are believed to trigger learners' autonomy. It shifts learners' roles, from the learner as the receiver of knowledge to the learner as the actor of the learning process-actively discovering rules (Motha, 2013).

In language education, induction is associated with a human's first language acquisition. That is to say, humans learn and acquire their first language implicitly and inductively. As Vygotsky (1986) explained, human cognition initiates from social communication and involvement in social activities. In the same light, Perfors (2014) maintained that children learn and acquire their first language by induction; they hear specific examples of phonemes, morphology, words, and sentences, from which they formulate the general principles of the language.

\subsection{Paper-based Instruction and Product-based Instruction (PPI \& PDI)}

The researcher designed and created Paper-Based Instruction (PPI) and Product-Based Instruction (PDI) in response to a call for a teaching approach that will ensure the transfer of skills taught in academic contexts to skills required in real business situations. Both instructional approaches embrace Rizzuto's (1970) inductive teaching philosophy, emphasizing learners' opportunities to discover knowledge. PPI and PDI give equal importance to lecturers' and students' skills to communicate dialogically and interrogate their learning process. Literature shows that dialogic communication and interrogation in the classroom, either student-student or teacher-student, play an essential role in students' knowledge acquisition. Rungwaraphong (2018) emphasized the importance of teacher's questioning skills, including choosing, crafting, and using questions with students to achieve learning goals. These skills determine both the quantity and quality of communication during the learning process. Dialogue differs from ordinary conversation or discussion in terms of the atmosphere and goal. It emphasizes the process of questioning and responding and welcomes different points of view regarding the disharmony of voices as an opportunity for deeper understanding (Rungwaraphong, 2018). Figure 1 illustrates tasks and learning activities underpinning each instructional module.

Each step in this diagram portrays the learning activities required for English writing. As illustrated in Figure 1, both inductive modules implemented in English writing cover eight steps, sharing five common procedures, while the differences exist in the other three procedures. Just like other inductive approaches, both the PPI and the PDI approaches showing, noticing, discovering, and discussing. Both 
inductive approaches require the students to notice and analyze examples of writing pieces; discovering writing rules occurs through this analysis. The differences between the two methods line in Steps 4, 5, and 8. After the discovery and formulation of rules in Steps 2 and 3, the medium for writing, the product to be written about, is introduced. In the PPI method, the students are given product factsheets, which contain detailed information pertaining to the product. In this light, the students perform the given product analysis but do so with the product images, not the authentic products.

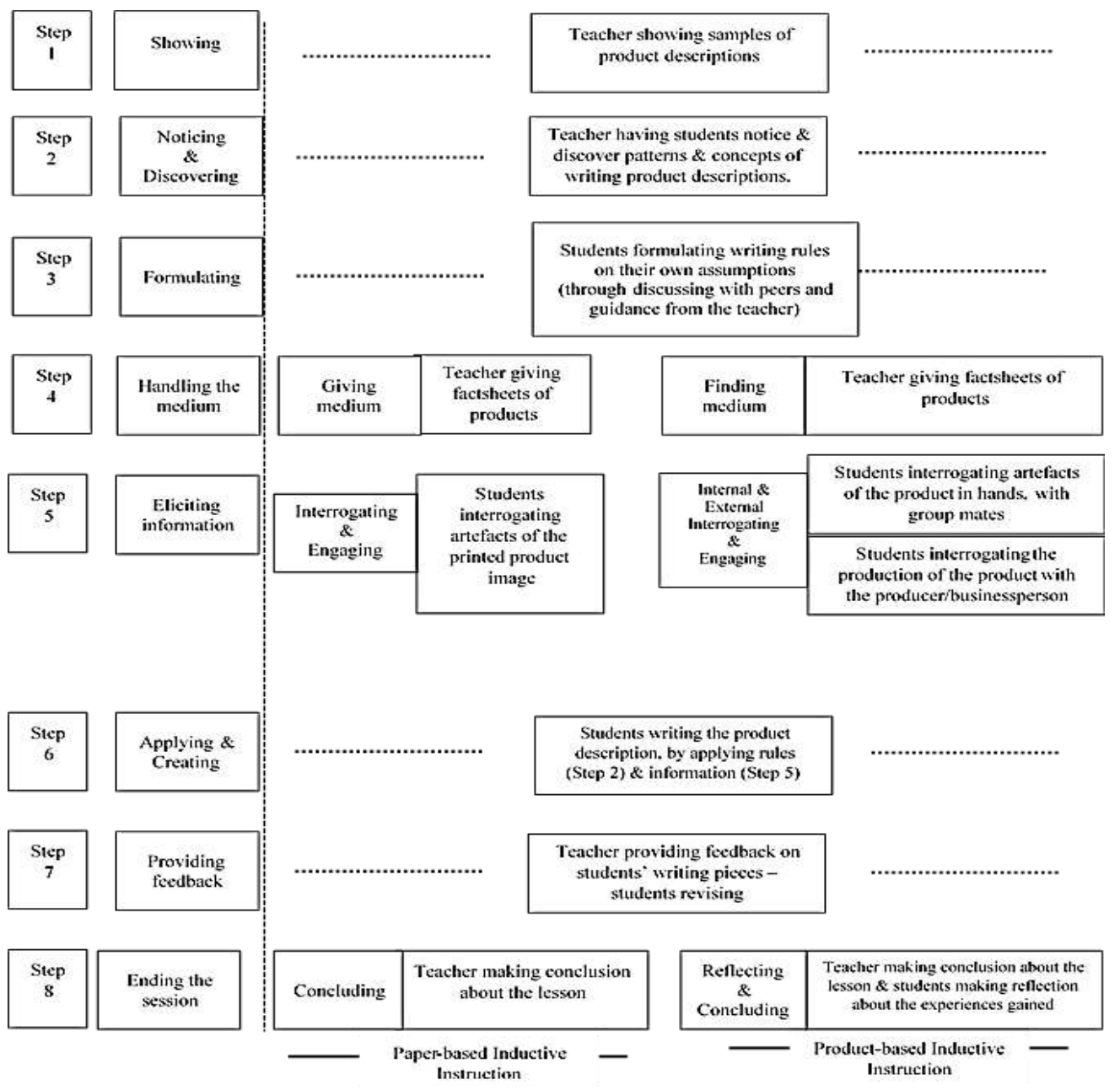

Fig. 1. Comparison of procedures and learning activities in PPI \& PDI modules

\subsection{Research Objectives}

The study aimed to investigate the two methods' dichotomy, examine practical issues of the implementation, including the challenges of each method, and give suggestions for English instructors who wish to adopt either of these two methods in their English writing class. The study specifically sought to answer the following three research questions:

1. What are the similarities and differences in the implementation between these two inductive modules?

2. What are the challenges of each inductive module?

3. Which approach is more appropriate for teaching English writing to Thai learners?

\section{Method}

\subsection{Participants and Setting}

The participants of the current study were 46 students from a Thai university. All of them were second-year Business English majors, aged approximately 19-20 years old. There were 10 (21.7\%) 
males and 36 (78.3\%) females. All of them have taken two business writing courses prior to taking part in the study: Fundamental English Writing in Year 1 and Business English Writing I in year 2.

The participants were randomly divided into two equal groups and put into two writing training modules: the paper-based module and the product-based module. The researcher organized the training and sought to prepare business students to be effective writers and give high proportions of interactions and decisions required in written communication in business environments.

\subsection{Data Collection}

Three data collection methods were applied in gathering the data to answer the research questions: (1) direct observation, (2) focused group discussion, and (3) students' writing scores. The collection methods will be discussed further in detail.

\section{1) Direct observation}

Direct observation is a data collection method in which the researcher acts as the evaluator, watching the subjects in their usual environment without intruding or intervening. This method aims to assess behavior, events, or situations that are going on in their natural environment (Adamson \& Wachsmuth,2017). As for the current study, the participants were directly observed during their participation in the learning activities in weeks 1-4. In each session, the researcher walked around the training room and observed each group while doing the assigned learning activities. The observations were overt, as the students were informed about the purpose of the observation. Data from the observations were collected through non-motion photos and recorded in the researcher's field notes, containing a list of processes or behaviors observed with space to record open-ended data.

\section{2) Focused group discussion}

Focused group discussion was adopted to gain an in-depth understanding of using inductive approaches in teaching English writing. The study carried out two group discussions - one discussion per module. Each discussion group consisted of four students; each group selected their representative to join the discussion. Questions asked in the discussion sought to elicit attitudinal responses and their perspectives on the instructional method they had experienced in the writing training. Importantly, they were asked to select the most preferred module and give reasons for the preference. Also, the participants were asked to report things they liked and disliked about each learning approach. The focused group discussions were administered in the final week of the research study and took about 20-30 minutes for each group discussion. The discussions were audio-recorded.

\section{3) Students' Writing Scores}

The students in both training modules were to achieve the same goal: writing a product description. The researcher assessed their product descriptions using the same scoring criteria, which was adapted from Huda and Gumilang's (2019) scoring rubric of writing test and Peter's (2016) blog on product description. The rubric assesses five elements of the strong product description, as illustrated in Table 1 .

\subsection{Research Procedure}

Each training module covered four weeks; there were two sessions a week, making eight sessions for each module. Each session was 45 minutes. Activities and tasks in both the PPI and PDI modules were organized around a cooperative learning ground. Students were divided into groups of 4-5 members and carried out the given assignments on a group basis. In this light, the writing assignments were done as a group assignment. Each module's implementation follows steps described in Paperbased Instruction (PPI) and Product-based Instruction (PDI). The observations were conducted once a week (in weeks 1-4) to collect data, making eight observations in total. In week five, the students completed their product description and submitted it to the researcher. The research was closed with the focused-group discussions in week six. The research procedure and data collection are presented in Figure 2. 


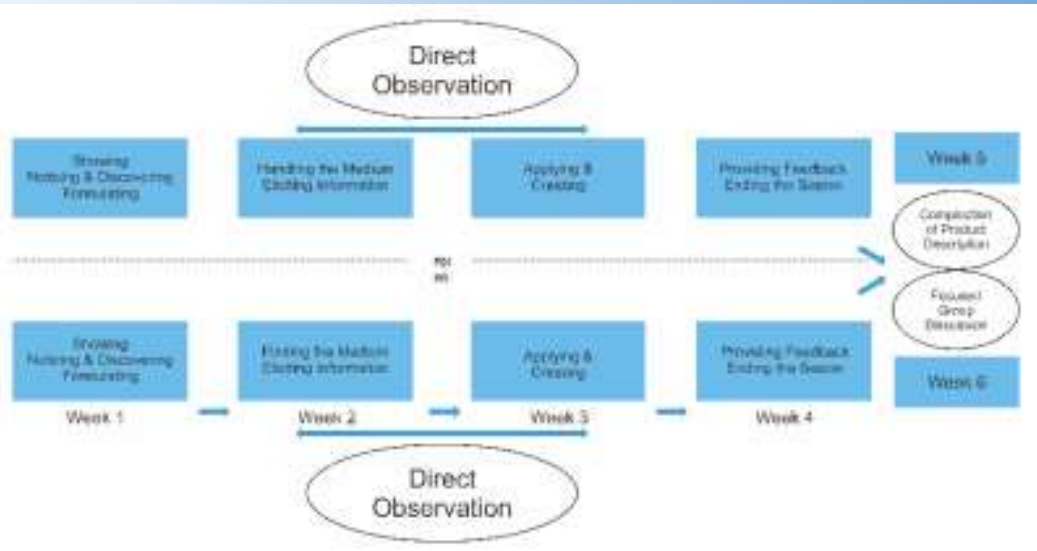

Fig. 2. Research procedures

Note. The diagram shows the research methods used throughout the study.

Table 1. Rubrics for Assessing the Product Description Assignment

\begin{tabular}{|c|c|c|c|}
\hline Components & Score & Level & Indicator \\
\hline \multirow[t]{4}{*}{ Content } & 4 & Excellent & $\begin{array}{l}\text { Present sufficient well-chosen information and features that focus on the } \\
\text { product's benefits and enable the reader to identify what the product is } \\
\text { within the title easily. }\end{array}$ \\
\hline & 3 & Good & $\begin{array}{l}\text { Present information and features about the product that partly focus on the } \\
\text { product's benefits and reflect the product }\end{array}$ \\
\hline & 2 & Fair & $\begin{array}{l}\text { Present some information and features about the product, which make it } \\
\text { hard for the reader to identify the product and perceive the benefits of the } \\
\text { product }\end{array}$ \\
\hline & 1 & Poor & $\begin{array}{l}\text { Present no clear information and do not include sufficient features of the } \\
\text { product }\end{array}$ \\
\hline \multirow[t]{4}{*}{ Vocabulary } & 4 & Excellent & $\begin{array}{l}\text { Use powerful words that sell; vocabulary chosen focuses on benefits and } \\
\text { results }\end{array}$ \\
\hline & 3 & Good & $\begin{array}{l}\text { Use words used that are not much powerful; and contain some errors in } \\
\text { vocabulary but not interfere with understanding }\end{array}$ \\
\hline & 2 & Fair & $\begin{array}{l}\text { Words used are dull and contain some errors sometimes in vocabulary that } \\
\text { sometimes interfere with understanding }\end{array}$ \\
\hline & 1 & Poor & $\begin{array}{l}\text { Contain many errors in vocabulary choices, which severely interfere with } \\
\text { understanding }\end{array}$ \\
\hline \multirow[t]{4}{*}{ Grammar } & 4 & Excellent & Good in grammar, no errors in grammar \\
\hline & 3 & Good & Contain errors in grammar but do not interfere with understanding \\
\hline & 2 & Fair & Contain errors in grammar that slightly interfere with understanding \\
\hline & 1 & Poor & Contain errors in grammar that severely interfere with understanding \\
\hline \multirow[t]{4}{*}{ Visual Appeal } & 4 & Excellent & $\begin{array}{l}\text { Include clear and appealing images that provide multiple angels of the } \\
\text { product so that the reader is induced to read the description of the product }\end{array}$ \\
\hline & 3 & Good & $\begin{array}{l}\text { Include images of the product, but not provide multiple angels of the } \\
\text { product }\end{array}$ \\
\hline & 2 & Fair & Include some images of the product \\
\hline & 1 & Poor & Do not have any image of the product \\
\hline \multirow[t]{4}{*}{ Organization } & 4 & Excellent & $\begin{array}{l}\text { The product's specs or features are well structured in paragraphs and bullet } \\
\text { lists in a way that engages the reader's emotion }\end{array}$ \\
\hline & 3 & Good & $\begin{array}{l}\text { The product's specs or features are well structured in paragraphs and bullet } \\
\text { lists, but not much engages the reader's emotion. }\end{array}$ \\
\hline & 2 & Fair & The product's specs or features are slightly scattered throughout the writing \\
\hline & 1 & Poor & $\begin{array}{l}\text { The product's specs or features are fairly scattered throughout the writing, } \\
\text { which looks confusing for the reader }\end{array}$ \\
\hline
\end{tabular}




\subsection{Data Analysis}

Data gathered from focused-group discussions were qualitative and were codified and analyzed by thematic analysis. Data gathered from direct observations were recorded in the researcher's observation field notes; non-motion pictures taken in training were cross-examined for comparison and contrast. Qualitative data from the focused-group discussions and observation field notes were analyzed thematically using the grounded theory, which seeks to construct or discover a theory from the data (Tie, Birks \& Francis, 2019). In the current study, substantive coding procedures were adopted. The line-by-line open coding of data and constant data comparison was carried out to ensure the data supported emerging categories and proceeded until a core category emerged. The basis of the emerging theory was done by selecting core categories and theoretically connect to other relevant categories. Once the relevant categories were saturated, the research is theoretically complete. The written product descriptions of each of the students' groups were given codes at the back of the paper so that the researcher did not know from which module of learning it was written. Each writing piece was then assessed using the scoring criteria adapted from Huda and Gumilang's (2019) scoring rubric of writing test and Peter's (2016) blog on product description.

\subsection{The Study's Trustworthiness and Credibility}

The trustworthiness and credibility of the current study were achieved through data triangulation and data saturation. Data can be triangulated when they are collected from multiple participants and by multiple methods. It can be called cross-examination and is a technique to double or even triplecheck the findings of a study (Nightingale, 2020). It is also a means to add richness and depth of the study (Heale \& Forbes, 2013). In the current study, validity occurs when data from different methods and participants yield the same results (Carter et al., 2014). Data saturation was the other technique employed in the current study to enhance the trustworthiness and credibility of the findings. This technique is regarded as the "gold standard" (Hancock et al., 2016) for analyzing qualitative data, enhancing the credibility of the research findings. In the current study, data saturation was achieved through focused-group discussions, in which questions were structured to facilitate asking different participants. The focused group discussion helped attain the truth through the discussion's openness and received multiple perspectives about the studied situation. Codes identified in the thematic analysis of the focused group discussion were also assessed for code saturation to ensure that the same category of codes would also be identified in the discussions from the other groups of participants (Hennink et al., 2017). Code saturation occurred when no further coding was identified. In this light, data saturation enabled the researcher to ensure the data adequacy, signifying that no information is missing and thus the findings are trustworthy (Faulkner \& Trotter, 2017).

\section{Findings and Discussion}

\subsection{Dichotomy and Similarity}

Photos taken during the observations and the researcher's views relevant to PPI and PDI modules are tabulated in Table 2. Table 2 illustrates the classroom dynamics that occur in both modules.

It could be noticed from the photos that although PPI and PDI modules were both inductively conducted in a cooperative ground whereby students carried out their tasks as a group, the overall dynamics were different. The different proportions of dynamics were displayed right away in the second step of the learning process: handling/finding the medium and eliciting information. First of all, classroom dynamics occur more when all students are involved in activities and discussions. PPI students were given the product's factsheets to be written about, which provided detailed information about the product and its production, as shown in Photo A. Further queries relevant to the product could be asked of the teacher. Unlike the PPI students, the PDI students had to leave the classroom environment and elicit information about the product's production with the product producer. In this light, the activity for eliciting information is performed by the students in the PDI module. It is to be noted that the information elicited by the PDI students was first-hand and authentic as it was either provided by the product producer or elicited through real engagement with the product (as shown in Photos $\mathrm{H}$ and I, in which the students examined the product). Table 2 shows that classroom dynamics also occurred through student-student interactions and student-teacher interactions. 
Table 2. Learning Activities Carried out by PPI and PDI Students

\begin{tabular}{ccc}
\hline $\begin{array}{c}\text { Inductive Learning } \\
\text { Process }\end{array}$ & $\begin{array}{c}\text { PPI } \\
\text { (Researcher's notes/images) }\end{array}$ & $\begin{array}{c}\text { PDI } \\
\text { (Researcher's notes/images) }\end{array}$ \\
\hline
\end{tabular}

Step 1: Showing, Same in both modules: students observed and analyzed examples of product descriptions noticing, discovering \& given by the lecturer. Then they discussed, wrote the pattern noticed, and formulated rules formulating and principles of the product description.

Step 2:

Handling/Finding the medium \& eliciting information
(1) Product Factsheet provided by a lecturer Photo A

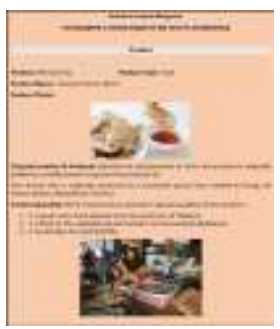

*Whole class got the same product factsheet of the same one product.

(2) More information can be acquired from the lecturer

(3) Discuss around factsheet

Photo B

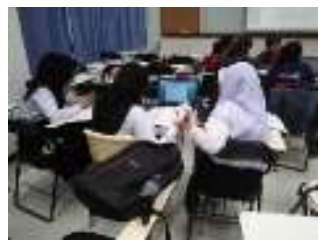

Photo C

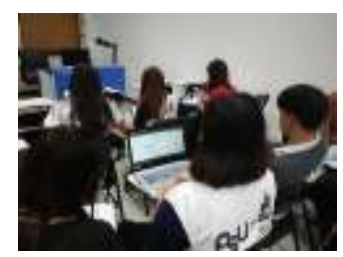

Step 3: Applying \& creating
(1) Students started writing the product description using information from the factsheet.

Photo D

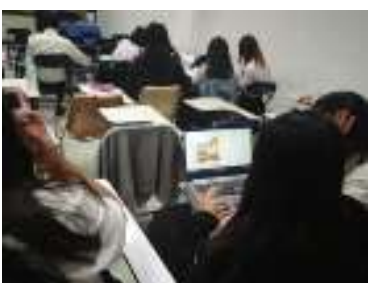

(1) Real products brought to class by the students

Photo F

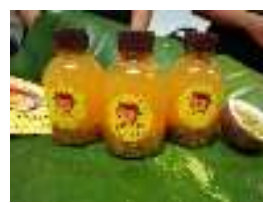

Photo G

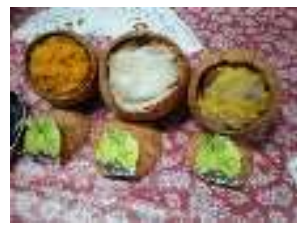

(2) Business owner / Product producer

(3) Discuss around real products

Photo H

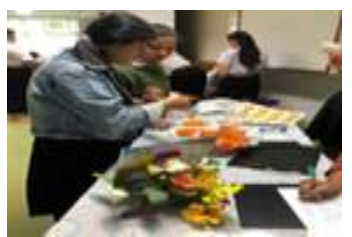

Photo I

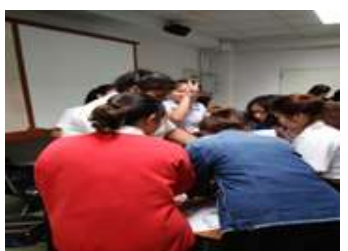

(1) Students started writing the product description while the real products still on the table

Photo J 
Photo E
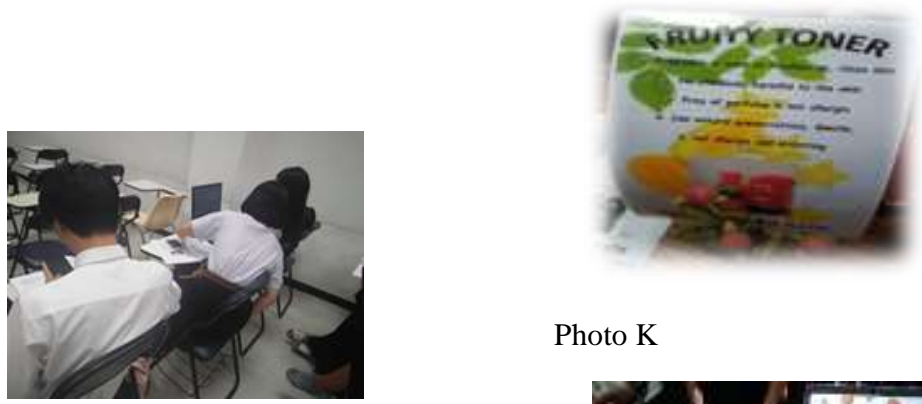

Photo K

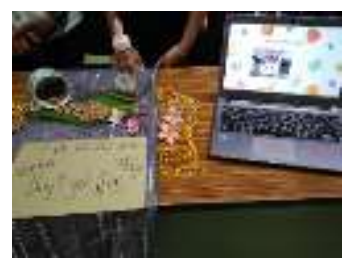

(2) Photo taken by the students and information about the production of image were applied in the writing

Photo L

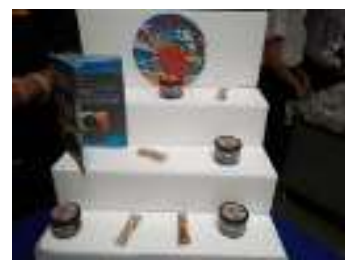

Photo M

Step 4: Providing feedback \& end the session
Same in both modules: Students from both modules handed it their product description to the lecturer to get feedback. Lecturer gave feedback and suggestions for revision.

It can be seen from photos in Table 2 that, while both PPI and PDI modules trigger the dynamics and positive atmosphere, the PDI session appeared to have more vigorous dynamics as student movements and interactions were relatively higher. While the real products were brought to the PDI session (Photos F and G), the factsheet (Photo A) that provided information relevant to the products was given to students in the PPI session. The PDI students moved around their products on the table while doing the learning task in Step 2 to touch, notice, or even to taste the edible ones and discussed them among their group members, as demonstrated in Photos H and I. In contrast, Photos B and C in the PPI module showed that the PPI students sat as a group, and their discussion was based on the given factsheet. The PPI students were unable to do what the PDI students did - touch, notice, or taste the real products - which are processes that appeal to human senses. Even in the writing process in Step 3, when each group in both PPI and PDI started to write using all the information they acquired in Step 2, the dichotomy clearly existed in both modules. As exemplified in Photos H, I, J, and K, each group's students still moved around the product in the PDI module. In contrast, as shown in Photos B, C, D, and E, students sat in a group and read the lecturer's factsheet in the PPI module. According to the researcher's field note: 
"The PPI students sat and discussed quietly as the information needed for writing was provided in the factsheet."

The statement shows that the PPI students did not have to or could not walk around to touch, notice, or taste the products. Results of the observation point that in the PDI module, the product's tangibility acts as a focal point on which to generate ideas and stimulate analysis and interrogations.

As for student engagement, Photos $\mathrm{H}$ and I illustrate the students' willingness to participate in given tasks in the PDI module compared to Photos D and E, which are learning activities in the PPI module. In the PDI's focused group discussion, one student reported that:

"Once that we agreed on which product we wanted to write about, my friends and I had to visit and interview the producer of the product. I think this is a learning activity that takes time and energy; it not just that we sit and write about a product. But we have to seek information about the product by ourselves."

Another PDI student supported:

"We put a lot of effort. We traveled to the product's factory, took pictures, and talked to the factory's owner. But that is not the end of the process. Before we traveled, we had to make lots of appointments, prepare list of questions, and plan everything beforehand. We felt stressed out and anxious, but overall it was fun to travel and talk."

Claims from these two students show students' persistence and effort, which, according to O'Donnell et al. (2011), are an indicator of behavioral engagement in learning while the students' perception of the overall enjoyment of the task, rather than the negative emotions such as stress or anxiety, indicates the emotional engagement. In addition, the learning in the PDI module is not confined to the boundaries of the classroom; instead, it situates students in authentic contexts. This finding underlines Lave and Wenger's (1991) Situated Learning, which posits that knowledge occurs when it takes place in authentic contexts. According to Kurt (2017), the learning occurs, and knowledge is developed in the situation that provides learners with situations similar to ones in the real world. In the researcher's field note, it was written that:

"During Step 2, PPI students do not look curious about the product they are going to write about. They read the factsheet quietly. Discussions with groupmate don't actually occur."

One PPI student reported in the focused group discussion that:

"To be honest, I felt so bored reading the factsheet. All the information we need to write about the product are provided in the factsheet. What should we be curious about?"

This claim firstly suggests that the PPI module prevents student involvement in Step 2 of the learning process, and secondly, the lack of involvement may lead to students' absence of curiosity. It may impair the students' engagement in the learning process in the long term. Furthermore, the absence of enjoyment suggests that the students are not emotionally engaged in the learning process (O’Donnell et al., 2011).

\subsection{PDI \& PPI Writing Scores}

The researcher assessed students' product descriptions using the scoring criteria adapted from Huda and Gumilang's (2019) scoring rubric of writing test and Peter's (2016) blog on product description. Students' written product description scores are displayed in Table 3.

According to Table 3, no PPI groups got "Good Level" in the writing assignment; 2 out of 4 writing pieces were rated "Fair" while the other two were rated "Poor" (PPI Groups B and C rated at 2.8 and 2.0, respectively, and PPI Group A and D were rated at 1.25 and 1.4, respectively). The product descriptions written by students in the PDI module, in contrast, were rated as "Good" in three groups; PDI Groups E, F, and G gave average scores of 3.0, 3.2, and 3.2, respectively. The product description written by the PDI Group H gave an average score of 2.6, and no work was rated as "Poor." 
Holistically, the PPI module's overall score was 2.05, rated as a "Fair" group level, while the overall score of the PDI module was 3.0, which was regarded as a "Good" group level.

Interestingly, Table 3 shows two writing elements rated at the same level in the two inductive modules: Grammar and Organization of students' writing pieces from both modules were equally rated "Poor" and "Fair," respectively. The visual element in the product description written by students from the PDI module, in contrast, was rated as "Good" (average 3.5) while that of the PPI students was regarded as "Poor" (average 1.5). Content and vocabulary of the writing pieces produced by the PDI students were rated "Good" (average 3.75 and 3.5, respectively). In contrast, those of the PPI students were regarded as "Fair" (average 2.25 and 2, respectively).

Table 3. $\quad$ PPI \& PDI Writing Scores

\begin{tabular}{|c|c|c|c|c|c|c|c|c|}
\hline $\begin{array}{l}\text { Group/ } \\
\text { Scoring } \\
\text { Criteria }\end{array}$ & $\begin{array}{l}\text { Content } \\
\text { (4) }\end{array}$ & $\begin{array}{c}\text { Vocabulary } \\
\text { (4) }\end{array}$ & $\begin{array}{c}\text { Grammar } \\
\text { (4) }\end{array}$ & $\begin{array}{c}\text { Visual } \\
\text { Appeal } \\
\text { (4) }\end{array}$ & $\begin{array}{c}\text { Organization } \\
\text { (4) }\end{array}$ & $\begin{array}{c}\text { Total } \\
\text { Score } \\
(20)\end{array}$ & $\begin{array}{l}\text { Average } \\
\text { (4) }\end{array}$ & $\begin{array}{l}\text { Group } \\
\text { Level }\end{array}$ \\
\hline PPI A & 2 & 2 & 2 & 1 & 3 & 10 & 1.25 & Poor \\
\hline PPI B & 3 & 3 & 2 & 2 & 4 & 14 & 2.8 & Fair \\
\hline PPI C & 2 & 2 & 2 & 1 & 3 & 10 & 2.0 & Fair \\
\hline PPI D & 2 & 1 & 1 & 2 & 1 & 7 & 1.4 & Poor \\
\hline $\begin{array}{l}\text { Average } \\
\text { Module }\end{array}$ & 2.25 & 2 & 1.75 & 1.5 & 2.75 & & & \\
\hline Level & Fair & Fair & Poor & Poor & Fair & & 2.05 & Fair \\
\hline $\begin{array}{l}\text { Group/ } \\
\text { Scoring } \\
\text { Criteria }\end{array}$ & $\begin{array}{c}\text { Content } \\
\text { (4) }\end{array}$ & $\begin{array}{c}\text { Vocabulary } \\
\text { (4) }\end{array}$ & $\begin{array}{c}\text { Grammar } \\
\text { (4) }\end{array}$ & $\begin{array}{c}\text { Visual } \\
\text { Appeal } \\
\text { (4) }\end{array}$ & $\begin{array}{c}\text { Organization } \\
\text { (4) }\end{array}$ & $\begin{array}{c}\text { Total } \\
\text { Score } \\
(20)\end{array}$ & $\begin{array}{l}\text { Average } \\
\text { (4) }\end{array}$ & $\begin{array}{l}\text { Group } \\
\text { Level }\end{array}$ \\
\hline PPI E & 4 & 3 & 2 & 4 & 2 & 15 & 3.0 & Good \\
\hline PPI F & 4 & 4 & 22 & 4 & 2 & 16 & 3.2 & Good \\
\hline PPI G & 4 & 4 & 2 & 4 & 2 & 16 & 3.2 & Good \\
\hline PDI H & 3 & 3 & 1 & 3 & 3 & 13 & 2.6 & Fair \\
\hline $\begin{array}{l}\text { Average } \\
\text { Module }\end{array}$ & 3.75 & 3.5 & 1.75 & 3.5 & 2.5 & & & \\
\hline Level & Good & Good & Poor & Good & Fair & & 3 & Good \\
\hline
\end{tabular}

\subsection{Challenges of Inductive Teaching in Thai Contexts}

Data from the focused discussions among eight representative students, together with data collected during the classroom observations, indicate two common challenges in implementing both inductive teaching methods while teaching English writing to Thai students. The likelihood that the students will notice and identify some patterns implicit in the examples shown becomes the first challenge found in both inductive modules. All eight students from both PPI and PDI similarly expressed this difficultly. For example, a PPI student reported that:

"We were given a variety of product descriptions, but so what is next? I mean what should we do next. What and where to start with?"

Likewise, a PDI student specified that:

"I feel like a good product description should use active voice, rather than passive voice. But I am not sure if this is really correct. Moreover, I don't know whether I should start with writing the introduction or just go straight to the product's ingredients."

The researcher's fieldnote supports students' claim:

"When the students were presented with examples of product descriptions, they looked quiet. They did not discuss among their groupmate. Maybe they did not know what should be discussed about or where to start."

This finding suggests that having to discover the rules on their own and experiment with how these rules work is too time-consuming for the students to achieve the task, and they are not sure whether or not the rules they have visualized on their own are accurate. The uncertainty about grammar 
accuracy is reflected in the students' writing scores (in Table 3), which illustrates that grammar is a weakness for students from both modules. Students' difficulties in detecting and formulating grammar and rules in writing on their own suggest that the direct, explicit teaching of writing may still be a pragmatic and preferable approach for Thai students.

In language education, explicit teaching is a structured form of instruction in which lessons and learning activities are purposefully designed and distributed to students. Even though explicit teaching is controversial due to its emphasis on memorization, drilling, and rule-governed learning activities, several studies indicate that explicit teaching can make lessons clearer, compared to implicit teaching (Forey \& Cheung, 2019), as it has emphases on modeling for students, i.e., showing them what and how to do a task. In the EFL context, particularly, literature has indicated the practicality and potentiality of employing explicit, instead of implicit, as a method of teaching a language (Tang, 2012; Yeung et al., 2016). The current study's finding suggests that the first step of both the PPI and PDI might need adjustment. Rather than being shown an example of writing, the students should be provided with worksheets or guidelines purposefully designed to help them quickly discover and formulate the writing rules on their own in a succinct amount of time. This requires more work and preparation on the teacher's part, who will provide a scaffold for the students.

Students' perception of learning as a burden was another challenge in implementing inductive PPI and PDI. Information elicited from the focused discussions with the PPI and PDI students pointed to how the students perceived the burden of learning was shifted from the teacher to them. One of the PPI students reported that:

\section{"My groupmates and I don't understand why we have to discover the writing rules on our own. I think the lecturer can do this for us."}

Rather than viewing PDI as a way to nurture their critical thinking skills, the students perceive higher burden of learning, as one of them elaborated on the tasks they were required to do:

"The list of what we have to do is long. I remember that week my friends and I stayed up midnight almost the whole week. I didn't know why we had to do this."

Another PDI student further supported this:

"On Task 1 don't you think it is easier and faster if the lecturer just tells us how to write a product description? On Task 3 I was excited that I didn't have to go to class in that week. We went out to the product's producer. But at the end of the day, we were very exhausted."

The students' elaboration in the above examples reflects the lack of understanding when using fundamental objectives of inductive instruction. The researcher's primary rationale for implementing PPI and PDI is to let learning occur "bottom-up," following Thornbury's (1999) proposition. However, students did not clearly understand why the learning sequences were changed, and the learning roles were shifted from the learner as the receiver to the learner as the discoverer of knowledge.

\subsection{PDI as an Effective Teaching Method}

The study results indicate that PDI has resulted in students having better writing skills and more classroom dynamics and engagement. The study found that PDI has some characteristics that reinforce the teaching of English writing. These characteristics include tangibility, authenticity, and contextuality.

\section{1) Tangibility}

The key to the PDI approach is that the products are tangible and appeal to the human senses. Its tangibility act as a focal point on which to generate ideas and stimulate analysis and interrogations. A commercial product selected and used in the PDI approach is tangible and can be perceived by the sense of touch, sight, or even taste (see Photos F and G in Table 2). In mathematics and science, abstract concepts are frequently taught and represented by tangible objects. Objects' tangibility is claimed to enable the students to make connections between mathematic concepts, which are usually abstract, with tangible, concrete objects and foster a more profound understanding. According to Antle and Wise (2013), tangibles serve as tools for thinking and foster connections between abstract 
concepts through concrete representations. In this light, the PDI approach persists that abstract, complicated concepts can be concretely represented through concrete, touchable, seeable, or edible products. In this regard, the product selected to use in the English writing class should be accessible to the learners, promote hands-on experiences, encourage exploration and reflection, and provide learners with the analyzing tools they require to accomplish the task.

\section{2) Authenticity}

One dichotomy of the two inductive methods examined in the current study lies in the authenticity of the medium used and the elicitation of information. In PPI, the target product's analysis is conducted with the printed image and the textual information provided by the teacher. Therefore, the analysis of the product in the PPI method is paper-based. Contrarily, the PDI method analyzes authentic, tangible products, allowing the students to see, touch, smell, squeeze, or, on some occasions, taste the product. The fact that the PDI students will be required to seek their own product, engage with the product, meet with the producer, and observe the product's production suggests that the PDI module situates students in real contexts. In this light, the PDI module provides students with opportunities to make real connections with what is learned in the classroom and what is required in the workplace (Meyers \& Lester, 2013). The students will be aware of the need to communicate as a professional in an authentic context. This provision of opportunities for making real connections reflects the lecturer's awareness of real business demands. According to Arputhamalar and Kannan (2015), the students need to be trained to meet those demands. In addition, PDI embraces Lave and Wenger's (1991) Situated Learning theory, which is a theory on how a person develops professional skills. Situated Learning focuses on experiential and situational activities and posits that learning occurs through social engagement and takes place beyond classroom boundaries, which could be in kitchens, gardens, sports centers, field trips, depending on the field of knowledge (Lave \& Wenger, 1991).

\section{3) Contextuality}

PDI embeds learning activities or assignments into meaningful and real context rather than being treated as mere learning activities or exercises in classrooms. In this way, PDI contextualizes its content and instruction, responding to Hollis-Turner and Scholtz's (2010) proposition, which underlines the need to design writing tasks that bridge the gap between writing in academic contexts and writing in real business contexts. It can be expected that PDI will be able to enhance students' capability to transfer what is taught in the classroom to what is required in the workplace. Thus, language activities and exercises are not isolated from real contexts and are contextualized. The significance of the effort that the PDI approach takes the students to learn and explore in the real context is the belief in the school or university classroom that the language input is mainly produced from the teacher or lecturer, who is not a real audience in the business environment (Al-Mohammadi \& Derbel, 2015). In addition, allowing students to immerse in the real working contexts reflects the partnership with the community in which the students live, which later on can enhance Situated Learning (Mayers \& Lester, 2013). Writing classes that do not follow PDI principles involve objects that the students have no experience with, leading the students' language output to be produced regardless of context. As such, the language input and output in classrooms is often de-contextualized. Decontextualized language instruction may be effective for young children's vocabulary acquisition in the early stages. As the ultimate goal of language learning in higher education is to use the target language correctly and appropriately in real contexts, the study results suggest that PDI is adopted because it does not confine business writing to the classroom; rather, this instructional approach provides opportunities for students to produce writing pieces based on information elicited from real contexts.

\section{Conclusion}

The study reported in this article sought to compare similarities and differences between two inductive teaching approaches adopted in a Business English writing training program in Thailand and identify which would be more effective. The study results indicate three features that distinguish PDI from PPI, including tangibility, authenticity, and contextuality and recommend Product-based Instruction (PDI) over Paper-based Instruction (PPI) as a more effective means for teaching Business English writing in Thailand. PDI features can optimize overall enjoyment and engagement in the learning process and provide opportunities for students to learn in authentic professional 
environments, contexts, and culture that is cast in real-life situations. The challenges of implementing both types of inductive instruction were also identified. This included the fact that both instructional modules are unable to strengthening students' grammar accuracy, which may be because the inductive instruction does not teach the grammar directly. The students' attitude toward inductive learning also needs to be changed; rather than viewing inductive learning activities as an extra burden, students should perceive this approach of learning as a way to learn and explore on their own which will lead to critical thinking skills. The challenges of inductive instructions addressed in this study suggest that future research needs to be completed to make PDI better in terms of grammar accuracy and explore ways to help change students' paradigm of inductive learning.

\section{Declaration}

Author contribution : The author confirms sole responsibility for the following: study conception and design, data collection, analysis and interpretation of results, and manuscript.

Funding statement $\quad:$ The research is non-funded.

Conflict of interest $\quad$ : The author declares no conflict of interest.

Additional information : No additional information is available for this paper.

\section{REFERENCES}

Adamson, R.M., \& Wachsmuth, S.T. (2017). A review of direct observation research within the past decade in the field of emotional and behavioral disorders. Behavioral Disorders, 39(4),181-189. https://doi.org/10.1177/019874291303900403

Albino, G. (2015). The effect of an explicit genre-based approach to teaching workplace writing. EdD thesis. The Open University.

Al-Mohammadi, S.A., \& Derbel, E. (2015). To whom do we write? : Audience in EFL composition classes. In: Methodologies for Effective Writing Instruction in EFL and ESL Classrooms (pp.197-208). https://doi.org/10.4018/978-1-4666-6619-1.ch012

Antle, A. N., \& Wise, A. F. (2013). Getting down to details: Using theories of cognition and learning to inform tangible user interface design. Interacting with Computers, 25(1), 1-20. https://doi.org/10.1093/iwc/iws007

Arputhamalar, A., \& Kannan, S.P. (2015). Growth of business English and the need to teach memo-writing skills to Indian tertiary-level learners. International Journal of English Language and Translation Studies, $3(2), 74-83$.

Carter, N., Bryant-Lukosius, D., DiCenso, A., Blythe, J., \& Neville, A. (2014). The use of triangulation in qualitative research. Oncol Nurs Forum, 41(5), 545-547. https://doi.org/10.1188/14.ONF.545-547

Faulkner, S.L., \& Trotter, S.P. (2017). Data saturation. Wiley Online Library. https://doi.org/10.1002/9781118901731.iecrm0060

Forey, G., \& Cheung, E. (2019). The benefits of explicit teaching of language for curriculum learning in the physical education classroom. English for Specific Purposes, 54, 91-109. https://doi.org/10.1016/j.esp.2019.01.001

Hancock, M. E., Amankwaa, L., Revell, M. A., \& Mueller, D. (2016). Focus group data saturation: A new approach to data analysis. The Qualitative Report, 21(11), 2124-2130. https://doi.org/10.46743/2160$3715 / 2016.2330$

Heale, R., \& Forbes, D. (2013). Understanding triangulation in research. Evidence-based Nursing, 16(4), 98. https://doi.org/10.1136/eb-2013-101494

Hennink, M.M, Kaiser, B.N., \& Marconi, V.C. (2017).Code saturation versus meaning saturation: How many interviews are enough? Qual. Health Res,27(4),591-608. https://doi.org/10.1177/1049732316665344 
Hollis-Turner, S., \& Scholtz, D. (2010). Business writing in academic and workplace contexts. Southern African Linguistics and Applied Language Studies, 28(3), 239-246. https://doi.org/10.2989/16073614.2010.545026

Huda, M. C., \& Gumilang, W.A. (2017). The effectiveness of using animation clips in teaching writing. Turkish Online Journal of English Language Teaching, 4(2), 63-79.

Kurt, S. (2017). Situated learning theory. in educational technology. Retrieved from https://educationaltechnology.net/situated-learning-theory/

Lave, J., \& E. Wenger. (1991). Situated learning: Legitimate peripheral participation. Cambridge, England: Cambridge University Press. https://doi.org/10.1017/CBO9780511815355

Nightingale, A. J. (2020). Triangulation. in: International Encyclopedia of Human Geography. Elsevier, pp. 477-480. https://doi.org/10.1016/B978-0-08-102295-5.10437-8

Nunan, D. (1999). Second language teaching and learning. Boston: Heinle.

Meyers, S., \& Lester, D. (2013). The effects of situated learning through a community partnership in a teacher preparation program. SAGEOpen, 1-9. https://doi.org/10.1177/2158244013497025

Motha, H. (2013). The effect of deductive and inductive learning strategies on language acquisition (Unpublished master's thesis). Tillburg University, Tillburg.

O’Donnell, A. M., Reeve, J., \& Smith, J. K. (2011). Educational psychology: Reflection for action. NY: John Wiley \& Sons.

Perfors, A. (2014). Induction in language learning. In In PJ Brooks and V Kempe (Eds.). Encyclopedia of Language Development (pp. 281-283). https://doi.org/10.4135/9781483346441.n90

Peter, H. (2016). Product descriptions: Elements and specifications. Retrieved from https://smarterecommerce.com/blog/en/ecommerce/product-descriptions-elements-and-specifications/

Rizzuto, F. M. (1970). Experimental comparison of inductive and deductive methods of teaching concepts of language structure. The Journal of Educational Research, 63(6), 269-273.

Rungwaraphong, P. (2018). Framework for dialogic teaching in English reading class: A practice guide for university lecturers. Journal of Humanities, 15(2), 59-76.

Rüütmann, T., \& Kipper, H. (2011). Teaching strategies for direct and indirect instruction in teaching engineering. In Interactive Collborative Learning (ICL) $201114^{\text {th }}$ International Conference on IEEE (pp.107-114). https://doi.org/10.1109/ICL.2011.6059556

deTang, E. (2012). To teach more or more to teach: Vocabulary-based instruction in Chinese EFL classroom. The Asian EFL Journal Quarterly, 14(1), 254-297.

Thornbury, S. (1999). How to teach grammar. Harlow: Longman.

Tie, Y.C., Birks, M., \& Francis, K. (2019). Grounded theory research: A design framework for novice researchers. SAGE Open Medicine, 7, 1-8. https://doi.org/10.1177/2050312118822927

Vygotsky, L. S. (1986). Thought and language. Cambridge: MIT Press.

Yeung, S. S., Ng, M. L., \& King, R. B. (2016). English vocabulary instruction through storybook reading for Chinese EFL Kindergarteners: Comparing rich, embedded, and incidental approaches. Asian EFL Journal, 18, 81-104. 